\title{
Engaging business: using practice-based experiential learning approaches to enrich MBA programmes
}

\author{
Justin O'Brien \\ Royal Holloway, University of London, UK \\ Donna Brown \\ Royal Holloway, University of London, UK
}

\begin{abstract}
This practice-oriented paper seeks to identify business engagement as a form of experiential learning and to share insights of an approach which was developed to enhance reflective practitioner opportunities for MBA students. The authors have significant experience in partnering, designing and delivering a variety of business engagement activities undertaken with postgraduate management students. This is collated as a reflexive review of attempts, across 20 iterations with a diverse range of partner organisations, to introduce and expand on elements of experiential learning within the authors' institution.
\end{abstract}

The paper's main contribution is the identification of opportunities and challenges involved in implementing and managing engagement with business to enrich the experience of Master in Business Administration (MBA) students. Firstly, a summary of the rationale for introducing different iterations of the business engagement approach is given. Then the paper seeks to identify a variety of potential hurdles and solutions associated with harnessing business engagement as a form of practical experiential learning, which are designed to illustrate the practicalities of implementing the approach for school, college and university professionals. Findings highlight implementation insights and the learning achieved by staff, students and business partners.

Keywords: business engagement; experiential learning; management education. 


\section{'The only source of knowledge is experience' (Einstein)}

\section{Introduction}

Whilst the opening quote may seem an extreme position, experiential learning approaches are particularly powerful; Bevan and Kipka (2012) posit that they can be effectively utilised in a wide range of management education fields. Whilst the rationale for utilising 'learning by doing' approaches appears robust and widely supported (Fenwick, 2003; McCarthy, 2010; Beard, 2010; Mughal and Zafar, 2011), evidence of UK university experiential learning in practice was found to be sparse (for examples see Beard and Wilson, 2005; Pedler, 2011). Using a qualitative approach to evaluation, this paper seeks to identify a variety of benefits and potential hurdles in maximising engagement with external organisations to enhance Master in Business Administration (MBA) students' teaching and learning. Building on Kolb's (1984) experiential learning theory, the paper examines participant reflections from twenty different business engagement activities, involving ten diverse organisations. Stakeholder insights were gleaned from student, teacher and business partner feedback during a five year period of planning, delivering and following up phases of engagement. Using a heuristic approach, supported by reflection on professional practice, we seek to encourage further experimentation with business engagement. Perhaps the key contribution offered by this paper is to further motivate wider innovation with forms of experiential learning in practice.

This paper seeks not to reiterate and reinforce the extensive literature on Kolb's experiential learning (see references below), but rather to offer colleagues practical insights into how they might embed business engagement into their own teaching practice. The paper starts by briefly discussing the original concept of experiential learning (Kolb, 1984) and its impact. One distinct form of experiential learning, business engagement, was introduced at this institution, with iterations integrated in to the MBA programme to allow postgraduate students, who already had considerable employment experience, to assume greater control of the learning process. The qualitative approach to evaluation of these iterations is outlined in the methodology section. There were a number of practical challenges faced in successfully facilitating a business engagement approach; considered first are a number of internal issues, followed by those experienced at the external interface. We conclude the paper with practical recommendations for course design. 


\section{Considering experiential learning}

In 2005, Kolb and Kolb reviewed the six original facets of experiential learning identified by Kolb (1984). The initial concept was built on six propositions; firstly, that learning should be a continuous process, based on ongoing feedback, rather than something measured at an end point. It was argued that 'all learning is relearning', which implies that students with work experience are at an advantage when applying academic concepts and models to business problems and could be expected to be more capable of the reflection needed to reconcile conflicting information (Kolb and Kolb, 2005, p.194). Kolb argued learning will involve emotional and perceptual involvement rather than a purely intellectual response, (Kolb, 1984; Kolb and Kolb, 2008). And finally, and of greatest relevance here, were the arguments that learning involves students in the co-creation of knowledge as they integrate and reconcile new and existing theory and experience. Whilst the attention of Kolb and Kolb (2005) subsequently shifted to the interaction of the transformation and absorption of experience, this paper is concerned with the operationalisation of the final two facets of Kolb's 1984 concept of experiential learning. How can engagement with external partners, organisations and businesses, be deployed to permit students to 'birth' new perspectives?

Consideration has been given to a number of related approaches that appear to derive from or are similar to Kolb's (1984) experiential learning theory and how and why these approaches might manifest themselves as part of an advanced learning programme. Valkanos and Fragoulis (2007) explain that experiential learning can be expressed in simple terms as a form of 'learning by doing', which seems to miss the importance of reflection and the conscious evaluation of the conflict between theory and real-world experience. Wilson and Beard (2003) posit that due to the centrality of experience in all learning, that learning and experience essentially mean the same thing, and are therefore a tautology. However, they conceptualise a learning-experience continuum typology with one extreme being that of pure knowledge dissemination, that might be typified as rote learning and the other purely reliant on learning by doing.

Experiential learning, according to Wilson and Beard (2003) offers a philosophical underpinning, an integrating framework if you will, which can help unify many different theories and offer a more practical orientation. Hodge et al. (2011, p.180), from their research using 230 participants across three Australian universities, argue that 'practice 
based learning exchanges clearly provide a powerful and highly valued learning experience for students'. They found that students 'can experience transformative and emotional elucidations of learning', leading to assumption, changing ways of thinking and altering students' world views (Hodge et al., p.167).

Hickcox (2002) identifies that educators can use experiential learning programmes, courses and tasks to engineer innovative interactions for both faculty and students. Valkanos et al. (2007) suggest that participative techniques integrated with experience can facilitate behavioural, attitudinal, skill and knowledge development linked to the workplace and in social contexts. Yet Hodge et al. (2011) found that extant experiential learning models underestimated the extent of multidirectional learning flows and co-learning.

Before moving on to consider the university graduate skills expectation gap that may exist between employers and educators, a number of key terms associated with experiential learning theory are briefly considered, namely; situated, authentic and action learning, reflective practice, and continuing and lifelong learning.

Lave and Wenger (1991) believe that learning is embedded in activity, context and culture and use the terminology 'situated' to encompass this. They believe that learning needs to be presented in an authentic context. Xu et al. (2012) explain authentic learning as a form of research skill enhancement achieved through simply exposing students to practical business contexts using guest speakers and field visits.

Action learning, as defined by Zuber-Skerritt (2002), would seem to represent a ruminative group based approach to Kolb's experiential learning concept and describe it as a reflective learning technique that utilises group discussion, discovery, experiment and error stepped iterations. Wilson and Beard (2003) argue that action learning and reflective practice are common variations of the symbiosis of practice and theory. Building on a somewhat clichéd notion that change is a defining factor of modern life, is the idea that successful individuals need to, in a continual self-directed process, engage themselves in continuing and lifelong learning. Yang states 'Even if educational institutions evolve and ensure newly minted workers are ready for employment, workers must continue learning throughout their lives to stay relevant' $(2013$, p.1). It would appear that learning how to learn is the crucial point here. 
MacGregor and Semler (2012) highlight that movement away from purely cognitive intellectual development has been underway for decades and that business education has already integrated a number of contextual learning approaches, but significantly they suggest that management education needs to go further than merely using the 1930's originating case method. The authors argue cogently in favour of engaging management students across a variety of intertwining levels that comprise a convergence of intellectual, behavioural, social and physiological elements to assist achieving the change and reflection needed.

The authors believe that many educators implicitly assume that a blend of traditional knowledge transfer techniques are enhanced and not replaced by the experiential. Notable by its absence in the literature is any consideration of the appropriate allocation of the balance of learning time across a term or semester, the optimal orchestration, for example longitudinal or capstone, nor the degree to which such techniques might be embedded and interconnected within the curriculum journey. This absence is perhaps further evidence of a lack of sufficient engagement and systemic experience in this important field. Kolb and Kolb (2005) also highlight certain areas where changes to institutional behaviours (across faculty, student and curriculum development) will enhance experiential learning; and evaluation of the innovations is advocated.

Whilst accepted as good practice in principle, it is the authors' contention, supported by MacGregor and Semler (2012), that a full range of experiential learning techniques have not been universally adopted in university management education. Therefore an examination of the use of in-business and with-business exchanges, to develop students' learning ability to integrate and reconcile new and existing theory and experience, and thus co-create knowledge, is provided below.

\section{The case for using business engagement as an experiential learning approach}

There appears to be a mismatch between what employers are looking for in graduates and the qualities developed in universities (Vasagar, 2011). Whilst some academics have discussed and advocated the concept of experiential learning to help to prepare students for employment, UK Commission for Employment and Skills (2016, p.3) stated 'a growing 
number of jobs are being left unfilled because companies can't find the right people with the right skills'. Similarly, Yang (2013, p.1) cites an important dis-connect between business and US university perceptions of graduate workplace preparedness: 'Employers report frustration at not finding skilled workers. Jobs wait to be filled - current job seekers just lack the right skills'. Indeed, Kumaraswamy and Chitale (2012) argue that in a context of rapid change, fulfilling industry's expectations requires academic institutions to adopt innovative learning systems.

Griffiths (2007) notes a historic, close, but uneasy relationship between professions and higher education institutes. Giffiths' bi-modal environment model powerfully illustrates the segregated, discipline-based approach to management used in many universities, which they believe is at variance to the complex and highly interconnected real world. According to Yang (2013) the root of the problem is that traditional universities were not designed for a dynamic environment where skill depreciation is rapid, so they are unable to keep pace with ever changing industry requirements. Perhaps the focus on academics' publishable research and developing new researchers is too strongly embedded.

Heron (1999) indicates that conventional cognitive learning approaches attach insufficient focus to whole person learning and posits that sense-making from in-person experience is instrumental in learning and change. More recently, Marzo-Navarro et al.'s (2009) study of the graduate skills gap corroborates the need for improved mastery of generic competencies that include practical training, adaptability, oral communication, workplace integration, and the application of practical knowledge. They identified a sparse academic literature addressing solutions to the void between a perceived gap between business needs and university educated graduate skill sets.

Tyran and Garcia (2005) identify the constant challenge for management educators to find ways for students to link skill acquisition to career success. They note that perhaps one of the important inhibitors is the laborious planning required to ensure that experiential learning activities are effective and useful. An Ashridge-EABIS study found that 70 per cent of senior executives agreed that experiential learning was an important element in developing crucial business changing mind sets and skills, whilst only 30 per cent felt the same about lecture-based learning (Gitsham and Lenssen, 2009). 
Whilst it might be argued that employers should shoulder more responsibility, rather than just waiting for work-ready graduates to drop off the education conveyor belt, Tholen (2014, p.1) counters, stating that 'a vast and rapidly growing body of literature on employability has emerged in the last 15 years across both the academic and popular management literature'. Snyder (2003) identified industry complaints about a lack of critical thinking and creative skills from students employed in entry-level managerial roles. Few companies integrate experiential learning for staff into their leadership development programmes as seriously as IBM and HSBC, according to Gitsham (2012, p.298), who reflects 'the learning programmes had a powerful impact and that a range of outcomes was achieved. The experiential, immersive experience was a fundamental factor in the achievement of these outcomes, from the perspective of participants'. The sample size for semi-structured interviews was small, but in tracking participants for up to three years following their immersion, Gitsham (2012) was able to explore the long term benefits and the importance of wider organisational receptiveness in maximising the value to the business.

MacGregor and Semler (2012) suggest that management education needs to go further than merely using the 1930's originating case method. They argue the importance of engaging management students across a variety of intertwining levels that comprise a convergence of intellectual, behavioural, social and physiological elements to assist achieving the change and reflection needed. Conversely, Hodge et al. (2011) challenge a popular perception of academics in isolated, ivory towers using traditional didactic techniques, discovering that business hosts, students and academics all teach and learn in experiential learning scenarios. Activity, they claim, that sees academics play a crucial role in real world learning. They believe that although learning in formal academic settings has changed significantly in recent decades, changes to what constitutes learning, notably in respect to experience-led and situated learning models, is challenging traditional universities' provision of purely academic programmes (Hodge et al., 2011).

Gitsham (2012) notes the growing recognition for a mind-set change and the development of wider skill sets, recommending the powerful role that experiential learning should have here. A number of campus-based activities would include experiential learning even when class room based, for example; case study, role play presentations and context based discussions. Interestingly, Tyran and Garcia (2005) formally identify activities such as; internships, business simulations, off-campus projects, mentoring and guest speakers in 
their consideration of experiential learning approaches. Additionally, Hickcox (2002) also mentions consulting, off-campus visits and discussions, which supports the idea that experimental learning approaches can use a blend of on- and off-campus delivery styles. There is perhaps an opportunity for universities to ensure a greater understanding, stakeholder engagement if you will, of the education value they provide to students, alumni and employers (Gitsham, 2012).

It appears evident from the academic literature that a strong case for further change is understood. Some may posit that a university education, underpinned by the rigour of empirical research, is different and superior to work-based training approaches popular in business. Systemic resistance here may be a material factor inhibiting change and the differing expectations may be a suitable topic for further research. The theoretical validity of experiential pedagogic approaches would seem to be accepted by many, with numerous examples of how different, rich learning environments can be engendered. However, a number of significant and valid inhibiting hurdles have also been identified in the primary research outlined below and perhaps others exist that are yet to raise their heads in publication. Whilst the cognitive case appears to be well made, it seems that widespread evidence supporting the actual behavioural and structural changes required to operationalise the gap closure are sparse.

\section{Implementing experiential learning with business partners}

\section{Why was experiential learning identified to address student engagement?}

The catalyst for exploring innovations in business engagement was dwindling attendance for the weekly Management School industry guest lecture series, primarily provided for the MBA programme. The observed student behaviour was paradoxically juxtaposed by attitudinal feedback requesting more opportunities to interface with business professionals. The 2010 MBA programme review survey (36 responses from a five cohort population of 150 current students and alumni) identified a number of very clear wants; $42 \%$ of respondents were keen to see more guest speakers; $61 \%$ identified a desire to engage in more practical activities; and $75 \%$ wanted to visit businesses in person. A different approach to traditional industry guest lectures was needed. 


\section{Negotiating and engaging with business partners}

In seeking to develop and grow innovative business-university relationships, we discovered, through several difficult early discussions with potential industry partners, that the terminology of 'experiential learning' was problematic. Even the more common 'action learning set' phraseology resulted either in an over simplification to 'learning by doing' or an uncomfortable explanation of Kolb's (1984) learning cycle that was greeted with glazed eyes. A more straightforward yet accurate explanation was needed that framed the opportunity as an easily orchestrated, low cost, immersive and meaningful encounter that ideally offered some value back to the partner organisation.

LeBeau and Bennion (2014) noted the use of community engagement and public engagement. By packaging the concept as business engagement we sought to emphasise active-not-passive and unpaid reciprocity as key elements. The crucial and perhaps subtle difference in the sales pitch was requesting business professionals not merely to contribute unilaterally, but to identify potential benefits for everyone as part of an equitable tripartite cashless exchange. This idea appears to accord with Hodge et al. (2011) who recognise the need for universities to facilitate and structure exchanges, build relationships and engender co-participation. Examples of co-operative or reciprocal academic and industry partnerships the authors experimented with include: industry guest lectures to coaching public speaking; framing a student consulting project as a dissertation; a half day in-company workshop to think out loud about current business problems; or engendering team work by creating and running a live business consultancy case study.

Unexpected benefits were observed amongst business participants including; positive feelings resulting from a return to a campus environment, gratification from peer-like engagements with faculty, the résumé kudos of being invited to be a university guest lecturer, and an altruistic glow from giving back to a local university. Others were perhaps more hard headed and instrumentalist in gleaning benefits from collaborations and using these as opportunities to identify future talent for their business and low cost consultancy.

\section{Engaging academic staff - challenges and model developed}

Initially a number of faculty staff indicated a lack of interest in off-campus visits and a dearth of external contacts drawn on to offer guest lectures. Clear student feedback and unequivocal recommendations from the School's MBA accrediting body AMBA were used 
as powerful justifications to negotiate the integration of field visits, which included a business focused international study week, and a stronger emphasis on the case teaching method during the curriculum redesign. The lead author, as MBA Director, encouraged staff by making introductions to potential new business partners and by emphasising that funding was always available to support new engagement activity.

Gradually the new approaches were adopted by most of the teaching teams. Many also reported deriving greater pleasure from interacting with and directing the students following the introduction of the innovations, in line with observation of Dewey (1916, cited Kolb and Kolb, 2005) that 'chalk and talk' approaches demoralise faculty as well as students. In addition to helping design and deliver the business collaborations, faculty were found to play an important role in engendering student reflexivity during and following business engagements, connecting experiential learning episodes back into relevant areas of the curriculum.

Thus having explored the evolution and development of the concept, by way of summary, business engagement is defined for the purposes of this pedagogic paper as the trilateral knowledge exchange model that organisations (considered to include commercial, public sector and third stream not-for-profits), groups of students and lecturers apply across a range of business contextualised learning activities.

Table 1 presents summaries of the engagement activities introduced in the School of Management to boost the students' experiential learning. 
Table 1. Business Engagement Innovations to boost Distance Learning (DL) and On-Campus (OC) MBA experiential learning.

\begin{tabular}{|c|c|c|c|c|c|c|c|}
\hline Year & Brewing Multinational & Theme Park & $\begin{array}{l}\text { Telcoms } \\
\text { Multinational }\end{array}$ & $\begin{array}{l}\text { Chemical } \\
\text { Coatings }\end{array}$ & $\begin{array}{l}\text { Engineering } \\
\text { Multinational }\end{array}$ & $\begin{array}{l}\text { Theatre / Drama } \\
\text { engagement }\end{array}$ & Craft Brewery \\
\hline 2010 & \multirow{3}{*}{$\begin{array}{l}\text { Three iterations of live } \\
\text { consultancy case studies } \\
\text { (CSR and digital } \\
\text { marketing) with DL } \\
\text { cohorts during summer } \\
\text { school residential }\end{array}$} & & & & & & \\
\hline 2011 & & & & $\begin{array}{l}\text { Offer plenary } \\
\text { workshop to DL } \\
\text { cohort }\end{array}$ & \multirow{2}{*}{$\begin{array}{l}\text { Guest lectures to } \\
\text { OC } \\
\text { OC Guest lecture } \\
\text { used as staff } \\
\text { development } \\
\text { presentation } \\
\text { coaching } \\
\text { exercise }\end{array}$} & & \\
\hline 2012 & & \multirow[t]{4}{*}{$\begin{array}{l}\text { Offer formative } \\
\text { consultancy to OC } \\
\text { cohorts (park visit, } \\
\text { senior management } \\
\text { briefing and group } \\
\text { consultancy } \\
\text { findings } \\
\text { presentation) }\end{array}$} & $\begin{array}{l}\text { Offer DL visit to } \\
\text { iconic } \mathrm{HQ} \\
\text { followed by } \\
\text { conference } \\
\text { event }\end{array}$ & $\begin{array}{l}\text { Deliver \& } \\
\text { assess OC } \\
\text { student } \\
\text { performance on } \\
\text { core course }\end{array}$ & & \multirow[t]{4}{*}{$\begin{array}{l}\text { Experimental } \\
\text { London theatre } \\
\text { experiences } \\
\text { connected to OC } \\
\text { open space drama } \\
\text { workshops } \\
\text { embedded into } \\
\text { curriculum }\end{array}$} & \\
\hline 2013 & & & \multirow[t]{2}{*}{$\begin{array}{l}\text { Two live } \\
\text { consultancy } \\
\text { case studies } \\
\text { with DL summer } \\
\text { school } \\
\text { residential }\end{array}$} & & & & $\begin{array}{l}\text { Factory tours } \\
\text { with } \\
\text { engagement } \\
\text { with founding } \\
\text { directors DL \& } \\
\text { OC }\end{array}$ \\
\hline 2014 & $\begin{array}{l}\text { Company visit including } \\
\text { CEO interaction for OC }\end{array}$ & & & & & & \\
\hline 2015 & & & & & & & \\
\hline
\end{tabular}




\section{Methodological approach}

The grounded case study research approach used data drawn from twenty different faculty organised, student-business interactions at a mid-sized English university. Collaborations with ten different global and national organisations took place over a five-year period, involving a range of small, medium and large, commercial and not-for-profit enterprises. The students had a minimum of three years post-graduate work experience with highly diverse industry, function and cultural backgrounds, studying on full-time and distance learning MBA International Management programmes.

The primary research data was collated from oral and e-mail based post-event unstructured free comment feedback from participating students, business partners and colleagues by the lead author who orchestrated and participated in all of the business engagement activities. Participants were invited to comment on what went well, what could be improved and to reflect on their learning. Clearly respondents were identifiable in their e-mail and conversational exchanges, but all sources have been anonymised when presented here. This qualitative and non-generalisable research methodology has been certified through the School of Management ethics committee approval process.

\section{Findings and recommendations}

The findings are presented in four parts, initially considering insights gleaned from managing business engagement projects, and this is followed with discussion of academic, student and business partner learning.

\section{Managing the project and learning from this}

Successful implementation of business engagement was found to require some important structural and behavioural changes. Aside from developing the established curriculum and ring-fencing the required resourcing, a number of important internal cultural inhibitors were identified, including: costs and inertia; logistical complexity; the need for cashless exchanges; and the ethics of immaterial labour. 


\section{Costs and inertia}

Travel time and costs militate against engaging in relationships with distant organisations; thus a strategy of looking for local partnering opportunities was found to be more effective. The first business engagement saw a half-day theme park visit take place early in the first term during the closed season, assuring free entrance and timed to sit well away from assignment deadline pressure (see column two of Table 1). Students were given a behind the scenes tour by a group of experienced senior park managers, who shared insights into how their business operated. This was followed by a visit to the thrills workshop, a large space used for educational visits and decorated with a range of props, posters and models, where the business questions were put across following a multi-media company presentation. Close geographic proximity helped make a follow-up on campus interaction feasible, after an assignment peak. This allowed student groups to present back their recommended approaches to questions set by the visiting company managers. Additionally students were also encouraged to visit the park in operation at their own expense, which the majority did. Students were able to gauge their own performance based on observing the company management's body language, questioning approach and evaluative oral feedback of their own and peers' presentations. Particularly effective groups were sometimes invited to represent their ideas to a senior management board. A few ideas were taken forwards and implemented. Most students commented that these encounters were particularly motivating. Overall, it was found that tourism and hospitality venues have scalable facilities that can offer heavily discounted prices for off-peak educational groups and were happy to tailor the experience to address required learning outcomes. Subsequent highly successful engagements have included partnerships with a local brewery and theatre.

To ease bureaucratic inertia, trialling without the additional pressure of adhering to formal assessment constraints and regulations was a lower risk, pragmatic approach. However, sometimes un-weighted programme elements were seen by students as optional or worthy only of limited engagement. Modest teaching-innovation funding to cover coach transportation and any off-peak entrance fee was found to greatly simplify planning arrangements.

\section{Logistics of time and space}

Finding suitable engagement windows outside assignment deadlines, in a congested teaching timetable, required some tenacity. The development of additional formative, nonassessed, interactions was not straight forward and subsequently led to the embedding of 
business-engagement activity into timetabled sessions. A typical MBA cohort of around 30 is often considered too big for most companies to host; they did not have rooms of that size and using smaller sub-groups required extensive logistical co-ordination that was often considered just too difficult. The use of micro and self-directed approaches was found to yield some surprisingly positive results, with cold-calling and networking approaches used by proactive student groups to self-select a suitable business to engage with. One enthusiastic group challenged with assessing one of London's tourist attractions elected to visit a public house adjacent to campus and then were surprisingly invited to a local craft brewery for a private tour, driven there by the landlord. Illustrating clearly a lesson about luck, relationships and seizing every opportunity.

\section{Cashless exchanges: do not ask for money}

It was found that income generating opportunities for sponsored students, gifted chairs and contributions to library funds were unattractive. One partner explained that 'I ask my CEO to allow me merely to spend time here' and another elucidated, 'There would have to be a bottom line benefit for me to be able to invest any of my budget. I just don't see that justification'. Successful exchanges were centred on the intrinsic value of knowledge transfer and looking to ensure an equitable exchange. However, requests for limited time commitments, manifested as both personal and corporate social responsibility, were more easily forthcoming than expected, and often offered proactively once the business engagement concept, based on trilateral knowledge exchange and experiential learning, had been explained.

\section{Ethics of immaterial labour}

It is important to consider the ethics of inviting students to offer their labour immaterially, particularly when the engagement offers a more structured consulting context. The use of some non-assessed course elements allowed students to opt out, although very few did, and it was clear that students valued this form of experiential learning so highly that they were not unduly concerned about working without payment. The activity was perceived as enrichment rather than exploitation. However, it was crucial to ensure an appropriate balance was achieved, with the centrality of student-learning a prime consideration. Engagement with notfor-profit organisations, which often rely on volunteer labour with a clear community minded purpose, offered a more ethically optimal collaboration. 


\section{What academics learned /gained}

\section{Size matters: impact asymmetry}

Whilst some faculty enjoyed some kudos from interactions with global brand names, big company engagements were often complex and it was difficult to get under the skin of tacit organisational considerations. Working with small and medium sized enterprises (SME), students were often able to engage with senior management or even the leadership team directly. This resulted in higher levels of commitment and easier co-operation across the organisation. Students working with a SME were often able to understand the whole business more quickly and have a greater chance of making meaningful, implementable recommendations.

\section{Networking terror}

Adoption of business engagement approaches requires some risk taking, even where a supportive culture and sufficient resources are available. A rather surprising finding was to discover that some experienced academics lacked a material external business network and/or felt they lacked the necessary skills to engage in networking activity, illustrated powerfully by this earnest statement 'My worst fear would be to walk into a room of strangers and be expected to talk to them'. Partnered collaborations, pairing the inexperienced with more experienced staff, and formal training activities were used to mitigate here.

\section{Building trust and commitment}

Bastow et al. (2014) suggest the challenge for management research 'impact' is a function of credibility and divergent time spans. We soon learnt to start small and not expect too much, too quickly. Hodge et al. (2011) identified that not every practice-based learning exchange goes to plan, so we grasped that we needed to work with rather vague and ambiguous objectives, what might be referred to as an emergent strategic approach. An important element of the 'trust development phase' was ensuring the establishment of realistic expectations pertaining to the level of problem solving that might be reasonably garnered from the students. Rather surprisingly business partners were considerably less guarded and more open than initially expected, 'I had assumed that company confidentiality would be a huge stumbling block. We never used our own confidentially agreement, and actually this was rarely an issue. In contrast to written information, in person exchanges were often detailed 
and candid and this level of trust and openness was something staff and students appreciated greatly'.

\section{Set expectations low and be flexible}

This was unlikely to be at the level or depth of professional consultancy. However, host organisation activities such as problematising, requiring useful introspection and opening up for external exchanges of ideas, were seen as key outcomes. Given very limited time to put across what were often complex issues, it was illuminating to note that business partners valued engaging in the process ahead of garnering specific recommendations.

\section{Currency and impact}

Although not everyone possesses the complex skill set to juggle student-client expectations to successfully deliver a live consultancy, participating teaching staff found their subject currency and credibility was enhanced, with some students noting that academic staff benefitted by becoming 'more aware about business operations'. Modest impact related scholarship was observed in the form of a number of published teaching case studies, business journalism and paid individual consultancy.

\section{What students learned /gained}

\section{Theory into practice: the importance of being real and live}

Students highlighted that the most significant benefit of business engagement was the opportunity to put theory into practice and obtain formative and summative feedback on their ideas from real business practitioners. One MBA candidate stated 'It was an excellent opportunity to practise our presentation skills, building from our personal development lectures. The presence of industry senior management listening to our ideas was very motivational' (O'Brien, 2012a). Whilst another said 'This exercise was a brilliant opportunity to put some of the theories we learnt in the MBA into practice. Ansoff's matrix, BCG boxes, SWOT \& PEST analysis, 5 Forces Model, Revenue Management, Corporate Social Responsibility... we had it all in our tool box and we did not shy away' (O'Brien, 2012b). A faculty observation noted that watching students prepare for their final presentations often brought on an electric-like buzz, a heady blend of nerves and excitement. Receiving 
immediate, direct feedback via both the spoken word and body language from highly credible business professionals considering current, important business challenges was particularly highly prized. A supportive MBA reflection stated 'I enjoyed the fact-gathering sessions and team brainstorming meetings where we had heated debates about what was potentially relevant to offer as solutions and what was not. In the end, the possibility of making a difference drove us. This was not just an academic exercise as our work and proposed solutions could be implemented by the businesses'.

\section{Management consultancy insight}

Others appreciated the insight the exercises gave them on management consultancy. 'We had to prepare and brainstorm ideas on how to resolve complex business challenges and this was no mean feat, as in some cases we lacked the expertise on their specific industries'. In working with a small company that did not know what they needed or wanted, students learnt that 'the basics are most valuable'. 'The mid-size project like [company name] was a business performance challenge that taught respect for the client and professionalism while managing circumstances that you might not like'. During 'the international strategy consultancy... [it] was the methodology challenge that tested our wits and humbled us [we learnt to focus on] what was best for the client's interest and not what we believed was the best idea'.

\section{What business partners learned /gained}

Initially several companies strongly questioned the motivation of their staff wishing to undertake university-based activities, struggling to appreciate the business benefits. But, a number of diverse forms of organisational value to help justify the time and modest expenses have been identified, most notably; the opportunity to investigate at the cost of 'only' staff time (no consultancy fees) a non-critical business problem, to facilitate a conversation that engenders knowledge transfer and staff development and catalysing some real business changes.

\section{Problem formulation: investigating non-critical business problems}

One of the more surprising insights from this research was the internal value to an organisation that happened before the engagement took place, in framing and being able to 
communicate the business problem clearly to outsiders. This is evidenced in the following direct quotes from business partners:

The engagement... created a focus for the business team to think about their current business transformation problem in a structured analytical way.

[Our] managers had to identify a present challenge to the business and quantify the problem.

Root cause analysis was required from involved managers to determine clearest layout of the problem. This was often important, as these problems had often not been explored fully because of internal pressures.

Additionally business participant leaders highlighted the value of having the time to look at problems that were neither trivial nor business critical:

The importance here was that the problems used were often issues that were too large for quick fixes but not overtly damaging enough to justify resource to change

The consultancy group has the time to consider the problem fully which a business often does not.

And finally:

Accessing the latest business school approaches and thinking [using a] free of charge methodology meant we were able to examine areas where we wouldn't have thought of engaging outside consultants [which we found] surprisingly beneficial.

\section{Facilitating conversation: enabling knowledge transfer and staff development}

One business partner stated 'we greatly valued the experience. The chance to interact with bright, young minds was genuinely useful and shining a spotlight on aspects of our business has identified a number of opportunities' (O'Brien, 2012c). Another stated 'it allowed everyone involved to reflect, in an open and objective and non-judgemental atmosphere, on what was happening within the business'. The engagement 'offered new perspective over problems and 
open debate over solutions generated by university groups'.

Several partners highlighted the benefit from their own intra-organisational dialogues.

Because student groups had very diverse cultural and professional backgrounds and lacked tacit internal business knowledge, slow, often iterative, conversations were needed, which 'resulted in real self-questioning' generating 'some surprising and valuable insights' and 'created conversations within the [company name] through different staff levels that wouldn't have taken place without the stimulus'.

All partners valued the conversational knowledge exchange but one partner primarily used a week long case study interaction on campus as an explicit team building and staff development vehicle which they found 'confidence boosting and insightful,... [which demonstrated] the value of formal MBA training'.

\section{Catalysing real business changes}

Whilst the conversation and idea exchange was the most highly valued benefit perceived, some partners were also able to point to their university interaction as catalyzing real business change. 'We saw one concise and developed [student] solution which has resulted in gradual adoption of its key principles by the business... the initial [student] groundwork was key to changes in business strategy'. Another evidenced alternative approaches that 'were taken back and used in our organisation'.

Lastly, drawing on the idiom which suggests remarkable insight can come 'out of the mouths of babes', a student during a consultancy interaction in front of the company's whole board, which at the time was made up of middle aged male engineers, asked a seemingly innocuous question 'why are there no females on the board and why no marketing director?'. One innocent question, but both ideas were acted upon within three months.

\section{Conclusion}

The academic literature suggests that students can benefit from a range of contextual learning experiences, but evidence of adoption of this powerful approach is meagre. This paper's key contribution is proposing the idea of business engagement, a trilateral knowledge 
exchange between students, business and faculty, that emphasises active-not-passive and unpaid reciprocity. Learning in a novel and meaningful commercial context can be highly motivational, which is evidenced in the participant reflections. MBA students valued the opportunity to put their theoretical knowledge into practice, working on live, real business problems and gaining insight into management consultancy.

Business partners benefitted by being challenged to formulate and communicate business problems, garnering value from their own intra-organisation conversations, as well as the external perspectives provided by freshly minted MBA students. The knowledge transfer exchange was also used as a talent recruitment opportunity and for staff and team development. There was also some modest evidence of interactions catalysing some real business change, validation of meaningful impact.

Implicitly this paper underscores the valuable currency faculty can gain from the external engagement required to facilitate business engagement. However, a number of important challenges for staff considering innovating their pedagogic practice have been highlighted. Internal organisational constraints identified include cultural inertia, access to financial resources, and logistical limitations. Resilient staff need to be able to harness their business networking capability, skilfully build trust and commitment with new partners, and carefully manage expectations from often cashless exchanges.

The reflections on practice presented above aim to inspire and enable management educators, and the authors recommend that they look to expand their use of business engagement more widely across their curricula.

\section{Acknowledgements}

The authors would like to acknowledge support offered by the journal editor and the willingness and enthusiasm demonstrated by the various colleagues, students and business partners who participated in the numerous business engagements that provided the context for this paper, often beyond the call of duty. 


\section{References}

Bastow, S., Dunleavy, P. and Tinkler, J. (2014) The impact of the social sciences: how academics and their research make a difference. London: Sage.

Beard, C. (2010) The experiential learning toolkit: blending practice with concepts. London: Kogan Page Ltd.

Beard, C. and Wilson, J. (2005) Experiential learning: a best practice handbook for educators and trainers. Bodmin: MPG Books.

Bevan, D. and Kipka, C. (2012) 'Experiential learning and management education', Journal of Management Development, 31(3), pp. 193-197.

Fenwick, T. (2003) Learning through experience: troubling orthodoxies and intersecting questions. Florida: Krieger.

Gitsham, M. (2012) 'Experiential learning for leadership and sustainability at IBM and HSBC', Journal of Management Development, 31(3), pp. 298-307.

Gitsham, M. and Lenssen, G. (2009) Developing the global leader of tomorrow. Berkhamsted: Ashridge and EABIS for the UN PRME.

Griffiths, R. (2007) 'Knowledge production and the research-teaching nexus: the case of the built environment disciplines', Studies in Higher Education, 29(6), pp. 709-726 [Online]. Available at: http://dx.doi.org/10.1080/0307507042000287212 (Accessed: 10 Oct 2017).

Heron, J. (1999) The complete facilitator's handbook. London: Kogan Page Publishers.

Hickcox, L. (2002) 'Personalizing teaching through experiential learning', College Teaching, 20(4), pp. 123-128. 
Hodge, P., Wright, S., Barraket, J., Scott, M. and Melville, R. (2011) 'Revisiting 'how we learn' in academia: practice-based learning exchanges in three Australian universities', Studies in Higher Education, 36(2), pp. 167-183. DOI: 10.1080/03075070903501895.

Kolb, D. (1984) Experiential learning: experience as the source of learning and development. Englewood Cliffs, NJ: Prentice Hall.

Kolb, A. and Kolb, D. (2005) 'Learning styles and learning sources: enhancing experiential learning in higher education', Academy of Management Learning and Education, 4(2), pp. 193-212.

Kolb, A. and Kolb, D. (2008) 'Experiential learning theory: a dynamic, holistic approach to management learning, education and development', in Armstrong, S.J. and Fukami, C. (eds.) Handbook of Management Learning, Education and Development. London: Sage, pp. 42-68.

Kumaraswamy, K. and Chitale, C. (2012) 'Collaborative knowledge sharing strategy to enhance organizational learning', Journal of Management Development, 31(3), pp. 308-322.

Lave, J. and Wenger, E. (1991) Situated learning: legitimate peripheral participation. Cambridge: Cambridge University Press.

LeBeau, Y. and Bennion, A. (2014) 'Forms of embeddedness and discourses of engagement: a case study of universities in their local environment', Studies in Higher Education, 39(2), pp. 278-293. DOI: 10.1080/03075079.2012.709491.

MacGregor, S. and Semler, K. (2012) 'Towards whole person learning through sustainable executive performance', Journal of Management Development, 31(3), pp. 231-242.

Marzo-Navarro, M., Pedraja-Iglesias, M. and Rivera-Torres, P. (2009) 'Curricular profile of university graduates versus business demands: is there a fit or mismatch in Spain?', Education and Training, 51(1), pp. 56-69. 
McCarthy, M. (2010) 'Experiential learning theory: from theory to practice', Journal of Business \& Economics Research, 8(5), pp. 131-140.

Mughal, F. and Zafar, A. (2011) 'Experiential learning from a constructivist perspective: reconceptualizing the Kolbian Cycle', International Journal of Learning \& Development, 1(2), pp. 27-37.

O'Brien, J. (2012a) MBA Students solve Thorpe Park Business Challenges. Available at: http://mbadirector.blogspot.co.uk/2013/11/thorpe-park-directors-set-royal.html (Accessed: 24 October 2017).

O'Brien, J. (2012b) Thorpe Park Business Engagement. Available at: https://mbadirector.blogspot.co.uk/2012/11/thorpe-park-royal-holloway-mbabusiness.html (Accessed: 24 October 2017).

O'Brien, J. (2012c) Thorpe Park: The Royal Holloway MBA business engagement. http://mbadirector.blogspot.co.uk/2012/11/thorpe-park-royal-holloway-mbabusiness.html (Accessed: 10 October 2017).

Pedler, M. (ed.) (2011) Action learning in practice. Farnham: Gower.

Snyder, K. (2003) 'Ropes, poles and space - active learning in business education', Active Learning in Higher Education, 4(2), pp. 159-167.

Tholen, G. (2014) 'Graduate employability and educational context: a comparison between Great Britain and the Netherlands', British Educational Research Journal, 40(1), pp. 117. DOI: 10.1002/berj.3023.

Tyran, K., and Garcia, J. (2005) 'Connecting coursework to real work: university alumni and friends as 'virtual' mentors to management students', Academy Of Management Annual Meeting Proceedings [serial online]. August C1-C6.

United Kingdom Commission for Employment and Skills (2016) Employer Skills Survey 2015: UK Results. Evidence Report 97, May. 
Valkanos, E. and Fragoulis I. (2007) 'Experiential learning - its place in in-house education and training', Development and Learning in Organizations, 21(5), pp. 21-23.

Vasagar, J. (2011) 'Universities minister warns of graduates' skills gap', The Guardian, 15 March [Online]. Available at:

http://www.theguardian.com/education/2011/mar/15/universities-minister-graduatesskills-gap (Accessed: 10 October 2017).

Wilson, J. and Beard, C. (2003) 'The learning combination lock - an experiential approach to learning design', Journal of European Industrial Training, 27(2/3/4), pp. 88-97.

Xu, J., Dinwoodie, J. and Chang, C-H. (2012) 'Seeing is believing: developing research skills in international maritime students through authentic learning', The International Journal of Management Education, 10(1), pp. 50-60 [Online]. Available at: http://dx.doi.org/10.1016/j.ijme.2012.02.005 (Accessed: 10 October 2017).

Yang, D. (2013) 'Can we fix the skills gap?', Forbes [Online]. Available at: http://www.forbes.com/sites/groupthink/2013/08/02/can-we-fix-the-skills-gap/ (Accessed: 10 October 2017).

Zuber-Skerritt, O. (2002) 'The concept of action learning', Learning Organization, 9(3), pp. 114-124.

\section{Author details}

Justin O'Brien is a Senior Lecturer (teaching focussed), Strategy and Marketing, at the School of Management, Royal Holloway, University of London.

Dr Donna Brown is a Senior Lecturer in the Accounting, Finance and Economics subject group at the School of Management, Royal Holloway, University of London. 